\title{
Optimización de parámetros para la propagación in vitro de Colobanthus quitensis (Kunth) Bartl.
}

\section{Parameters optimization for in vitro propagation of Colobanthus quitensis (Kunth) Bartl.}

\author{
Marely Cuba-Díaz*, Daniela Acuña, Cristian M. Cordero \& Macarena Klagges
}

Laboratorio de Biotecnología y Estudios Ambientales, Departamento de Ciencias y Tecnología Vegetal, Escuela de Ciencias y Tecnologías, Universidad de Concepción, Campus Los Ángeles. Juan Antonio Coloma 0201, Los Ángeles, Chile.

*mcuba@udec.cl, mcubaster@gmail.com

\begin{abstract}
RESUMEN
Colobanthus quitensis es una de las dos plantas vasculares nativas que habitan en la Antártica. Además, se distribuye desde el sur de México hasta el norte de la Península Antártica y desde los 0 hasta los 4.200 m s.n.m., siempre en hábitats extremos. Es considerada una especie modelo para estudios en estrés abióticos. Debido a su pequeño tamaño y la poca accesibilidad a sus hábitats es necesario disponer de métodos eficientes de propagación para mantenerla en el laboratorio. El objetivo del presente trabajo fue optimizar algunos parámetros críticos en la propagación in vitro de esta especie relacionados con aspectos físicos y químicos para evitar efectos negativos como el amarillamiento y muerte de explantes y mejorar el condicionamiento de las nuevas plántulas, así como la respuesta a diferentes combinaciones hormonales. Se utilizaron explantes provenientes de plántulas previamente establecidas in vitro. La cobertura de los frascos con doble capa de papel aluminio evitó la pérdida de agua en el medio y en los tejidos, así como también disminuyó el amarillamiento de los brotes. La adición de tiosulfato de plata al medio estimuló la regeneración de brotes y raíces, en la concentración de 10 $\mu \mathrm{M}$ inhibió en un $50 \%$ y un $25 \%$ el amarillamiento y muerte de brotes, respectivamente. A los 28 días de cultivo en el frasco de vidrio se observó $49 \%$ menos de amarillamiento, $7 \%$ más de nuevos brotes y $24 \%$ de raíces que en la caja Magenta. La intensidad lumínica entre los 28-45 $\mu \mathrm{mol} \mathrm{m}-^{2} \mathrm{~s}^{-1}$ disminuyó los efectos negativos y estimuló la regeneración. C. quitensis responde a diferentes combinaciones hormonales, pero más estudios son necesarios para establecer la combinación óptima para los individuos provenientes de los diferentes hábitats.
\end{abstract}

Palabras clave: Cobertura, tipo de recipiente, intensidad lumínica, tiosulfato de plata, micropropagación.

\begin{abstract}
Colobanthus quitensis is one of the two native vascular plants that inhabit Antarctica. In addition, it spreads from the south of Mexico to the north of the Antarctic Peninsula and from 0 to $4200 \mathrm{~m}$ asl, always in extreme habitats. It is considered a model species for abiotic stress studies. Due to its small size and low accessibility to its habitats, efficient propagation methods are required to maintain it in the laboratory. The aim of this work was to optimize some critical parameters in the in vitro propagation of this species related to physical and chemical aspects to avoid negative effects such as explants yellowing and death and improve the conditioning of new plantlets, as well as response to different hormonal combinations. Explants from previously established in vitro seedlings were used. When the vessels were covered with a double layer of aluminum foil, water loss in the medium and the tissues was avoided, as well as the yellowing of the buds was reduced. The addition of silver thiosulfate to the medium stimulated the regeneration of buds and roots, and at a concentration of 10 $\mu \mathrm{M}$ inhibited the yellowing and death, of buds by $50 \%$ and $25 \%$, respectively. At 28 days of culture in the glass vessels, $49 \%$ less yellowing was observed, $7 \%$ more new buds and $24 \%$ more roots than in the Magenta box. The light intensity between 28-45 $\mu \mathrm{mol} \mathrm{m}-{ }^{2} \mathrm{~s}^{-1}$ decreased the negative effects and stimulated regeneration. C. quitensis responds to different hormonal combinations, but more studies are needed to establish the optimal combination for the individuals originated from different habitats.
\end{abstract}

KEYwoRDs: Coverage, vessel type, light intensity, silver thiosulfate, micropropagation. 


\section{INTRODUCCIÓN}

Colobanthus quitensis (Kunth) Bartl. (Caryophyllaceae) es la única dicotiledónea nativa de la Antártica, donde crece junto a Deschampsia antarctica Desv. (Poaceae), siendo las únicas dos plantas vasculares nativas que se desarrollan en este territorio. El territorio antártico se caracteriza por presentar bajas temperaturas todo el año, fuertes vientos y radiación elevada (Convey 1996). Para las plantas, el ambiente es más estresante aún, con déficit hídrico, aerosoles de agua salada, baja disponibilidad de nutrientes y cobertura de nieve durante prácticamente todo el año (Alberdi 2002, Chwedorzewska 2009). Todo esto ha llevado a que estas plantas desarrollen mecanismos moleculares, bioquímicos y fisiológicos que les han permitido la sobrevivencia en su hábitat extremo (Cuba-Díaz 2011). C. quitensis, además, presenta una amplia distribución latitudinal, desde el sur de México $\left(17^{\circ} \mathrm{N}\right)$ hasta el norte de la Península Antártica $\left(68^{\circ} \mathrm{S}\right)$, y altitudinal que van desde el nivel del mar hasta los 4200 m s.n.m. (Moore 1970, Smith 2003). En Chile, ha sido descrita en todas las regiones del país, exceptuando sólo la Región del General Bernardo O'Higgins, siempre en hábitats de condiciones ambientales extremas (Moore 1970).

La capacidad de $C$. quitensis de adaptarse a condiciones abióticas tan diversas, hace considerarla como una planta modelo para estudios sobre mecanismos ecofisiológicos y moleculares de adaptación al estrés. Se ha descrito una amplia diferenciación morfológica en esta especie, lo que sugiere formación de ecotipos (Smith 2003, Gianoli et al. 2004, Cordero 2012). Los estudios en esta especie se han enfocado principalmente en las poblaciones antárticas y una población andina que se ha descrito en las cercanías del cerro La Parva, en Santiago. Recientemente se ha estudiado una población de las cercanías de Punta Arenas (Cuba-Díaz 2011).

En la Antártica se ha podido establecer que con el reciente incremento de la temperatura, se han favorecido las condiciones para el desarrollo de nuevas poblaciones y un aumento en el número de individuos de la especie (Ruhland \& Day 2001). También se ha descrito la presencia de un abundante banco de semillas con un alto número de éstas, pero con una baja capacidad de germinación (McGray \& Day 1997, Ruhland \& Day 2001) y que la reproducción es mayormente vegetativa. Para los diferentes estudios que se llevan a cabo con esta especie, garantizar el número de plantas adecuadas constituye un desafío, considerando además su pequeño tamaño con cojines de aproximadamente $10 \mathrm{~cm}$ de diámetro y ramas que alcanzan entre los 0,5-2 cm (Moore 1970). Normalmente en los laboratorios donde se trabaja con esta especie se le propaga vegetativamente en condiciones controladas, pero a pesar de que su reproducción no es difícil, sí es variable durante todo el año, donde no se logra un número estable y elevado de individuos. Se le ha considerado como una especie muy poco viable y difícil de mantener en cultivo in vitro (Zúñiga et al. 2009), lo que implica el desarrollo de nuevas estrategias de establecimiento bajo condiciones de ambiente controlado. Por otro lado, en nuestro laboratorio se cuenta con una colección de individuos de 6 poblaciones (dos antárticas, dos andinas y dos patagónicas), esto nos ha permitido observar que los individuos correspondientes a diferentes poblaciones tienen distintas tasas de crecimiento bajo condiciones similares y no presentan la misma respuesta a las combinaciones de medios de cultivo usados. El desarrollo de protocolos de cultivo de tejidos apropiados, además de permitir la propagación masiva de plantas, especialmente de especies de difícil propagación por otros métodos, permite obtener individuos libre de contaminación por patógenos y facilita el control de factores que afectan el crecimiento de la especie (Pierik 1987).

El objetivo de esta investigación es controlar aspectos físicos y químicos, así como la respuesta al medio de cultivo de $C$. quitensis durante el establecimiento de parámetros generales en el cultivo in vitro de la especie, los cuales permitirán el desarrollo futuro de protocolos de cultivo in vitro específicos para las diferentes poblaciones de $C$. quitensis y así lograr obtener un número elevado de ejemplares de cada una de éstas, como una herramienta para la investigación en esta especie considerada modelo para estudios de adaptaciones vegetales a hábitat extremos.

\section{MATERIALES Y MÉTODOS}

Material Vegetal

Se utilizaron plántulas cultivadas in vitro de diferentes poblaciones de Colobanthus quitensis, aunque en este estudio en particular no se tomó en cuenta el factor poblacional y la mayoría de los estudios se realizaron con individuos de dos poblaciones provenientes de la Región de Magallanes y la Antártica Chilena, identificadas en el laboratorio como población de La Marisma (pPA) y población de La Vega $(\mathrm{pV})$. Individuos de ambas poblaciones son mantenidos en frascos de vidrio de $100 \mathrm{ml}$ con $25 \mathrm{ml}$ de medio de cultivo MS (Murashige \& Skoog 1967), complementado con BAP $0,5 \mathrm{mg} \mathrm{L}^{-1}(2,2 \mu \mathrm{M})$, sacarosa al $3 \%$ y agar al $0,7 \%$, pH 5,7 . Todos los medios son esterilizados en autoclave a $121^{\circ} \mathrm{C}$ y $1 \mathrm{~atm}$. por $15 \mathrm{~min}$. Los subcultivos en este medio se realizaron cada 5 semanas. Estas plantas son mantenidas en una cámara de crecimiento a $20 \pm 2^{\circ} \mathrm{C}$, con fotoperiodo de 16/8 h luz/oscuridad.

Disminución de Síntomas de Amarillamiento (Senescencia PRECOZ)

Prueba de cobertura: Con el propósito de incrementar el intercambio de gases para disminuir el amarillamiento de brotes y plántulas, se utilizaron coberturas de doble capa 
de papel Kraft o de doble capa de papel aluminio. Se utilizaron plantas de la población pPA en los mismos frascos y medio descritos previamente. A los 14 días se evaluó: amarillamiento de las plántulas o brotes, absorción de agar y pérdida de vigor hídrico en los brotes (arrugamiento).

Efecto del Tiosulfato de plata (STS): Otro aspecto considerado como posible causa del amarillamiento de plántulas fue la acumulación de etileno en el frasco de cultivo. Por lo que al medio de cultivo, anteriormente descrito, se le adicionó STS en las concentraciones de 0, 1,10 y $30 \mu \mathrm{M}$. Para el ensayo se utilizaron plántulas de la población pPA. A los 14 y 28 días se evaluó: amarillamiento de plántulas o brotes, $\mathrm{N}^{\circ}$ de brotes nuevos, $\mathrm{N}^{\circ}$ de raíces nuevas y síntomas de estrés (aparición de flores y muerte de plántulas).

EFecto de las CONDiciones DE CULTIVo SOBRE EL DESARROLlo DE LAS PLÁNTULAS

Efecto del frasco de cultivo: Se evaluó la calidad de las plántulas en frascos de vidrios de $100 \mathrm{~cm}^{3}$ y cajas Magentas ${ }^{\circledR}$ GA7 (Phytotechnology Laboratories). Se utilizaron 3 recipientes de cada uno con los mismos medios descritos anteriormente y plántulas de la población pPA. Se evaluó: amarillamiento de plántulas o brotes, $\mathrm{N}^{0}$ de brotes nuevos, $\mathrm{N}^{\mathrm{o}}$ de raíces nuevas y síntomas de estrés (aparición de flores y muerte de plántulas) por 42 días, realizando evaluaciones cada 14 días.

Efecto de la intensidad lumínica: Con ayuda de un fotómetro con un sensor cuántico LiCor (LI190SA quantum sensor) se midió la intensidad lumínica que reciben los frascos en las diferentes posiciones dentro de la cámara de crecimiento, comprobándose que las plantas reciben diferentes intensidades de acuerdo al lugar físico que ocupan, con una variación entre diferentes puntos que van desde los 28 hasta los $77 \mu \mathrm{mol} \mathrm{m}{ }^{-2} \mathrm{~s}^{-1}$. Tomando en cuenta esto, se usaron tres puntos dentro del cuarto de crecimiento donde las intensidades fluctuaban entre $\operatorname{los} 28 \pm 0,5 \mu \mathrm{mol} \mathrm{m}^{-2} \mathrm{~s}^{-1}$, los $45 \pm 2 \mu \mathrm{mol} \mathrm{m}{ }^{-2} \mathrm{~s}^{-1}$, y los $72 \pm 2 \mu \mathrm{mol} \mathrm{m}{ }^{-2} \mathrm{~s}^{-1} \mathrm{y}$ se ubicaron al azar 3 frascos recién propagados (entre 1 semana a cinco días) de las poblaciones $\mathrm{pPA}$ y $\mathrm{pV}$ indistintamente, sin considerar el efecto de población. Cada 7 días y hasta el día 21 se evaluó: amarillamiento de plántulas o brotes, $\mathrm{N}^{\circ}$ de brotes nuevos, $\mathrm{N}^{\circ}$ de raíces nuevas y síntomas de estrés.

Respuesta al medio de cultivo

Para evaluar la respuesta al medio de cultivo en nuestras condiciones de estudio, se probaron tres medios diferentes (Tabla I), dos informados con buenos resultados para la especie (población antártica) (Zúñiga et al. 2009) y el medio normalmente en uso de nuestro laboratorio.

Se utilizaron plántulas provenientes de la población pPA. La preparación de los medios de cultivos y las condiciones de crecimiento se realizaron como se mencionó previamente y fueron consideradas las condiciones que mostraron los mejores resultados en los estudios anteriores, excepto para la aplicación del STS. Se evaluó: amarillamiento de plántulas o brotes, $\mathrm{N}^{\circ}$ de brotes nuevos, $\mathrm{N}^{\circ}$ de raíces nuevas y síntomas de estrés cada 14 días y hasta los 42 días.

DiSEÑO EXPERIMENTAL Y ANÁLISIS DE DATOS

La asignación de los tratamientos a las unidades experimentales fue al azar, usando 3 frascos por cada tratamiento evaluado y 8 plantas por frasco. Los datos fueron analizados descriptivamente usando la media de cada tratamiento \pm ES. Los análisis de datos y la obtención de los gráficos fue desarrollado utilizando el programa Graph Pad Prism, versión demostración, 6.0 para Windows (GraphPad Software, La Jolla California USA, www.graphpad.com).

\section{RESULTADOS}

Pasados los catorce días, los frascos cubiertos con papel kraft mostraron severos síntomas de daño, con amarillamiento en el $100 \%$ de las plántulas y una considerable pérdida de agua tanto en el medio de cultivo como el tejido de las plántulas (Fig. 1). No se observó aparición de nuevos brotes con ninguna de las dos coberturas, lo que puede deberse al corto periodo de la evaluación. En cambio, con la cobertura de papel aluminio sólo se observó un $25 \%$ de amarillamiento, sin pérdidas en la turgencia del medio de cultivo ni de los tejidos de las plántulas.

TABLA I. Medios de cultivos evaluados en plántulas de Colobanthus quitensis población pPA. a: Zúñiga et al. 2009; b: Medio de cultivo establecido en el laboratorio (M. Cuba). BAP: Bencilamino purina.

TABLE I. Culture media evaluated in pPA population Colobanthus quitensis seedlings. a: Zúñiga et al. 2009; b: Culture medium set in the laboratory (M. Cuba). BAP: Benzylamino purine.

\begin{tabular}{cccc}
\hline SacAROSA \% & AgAR \% & Hormona $\left(\mathrm{mg} \mathrm{L}^{-1}\right)$ & PH \\
\hline 4 & 0,8 & Kinetina $(2)^{\mathrm{a}}$ & 4,5 \\
4 & 0,8 & Kinetina $(2)^{\mathrm{a}}$ & 5,6 \\
3 & 0,7 & BAP $(0,5)^{\mathrm{b}}$ & 5,7 \\
\hline
\end{tabular}




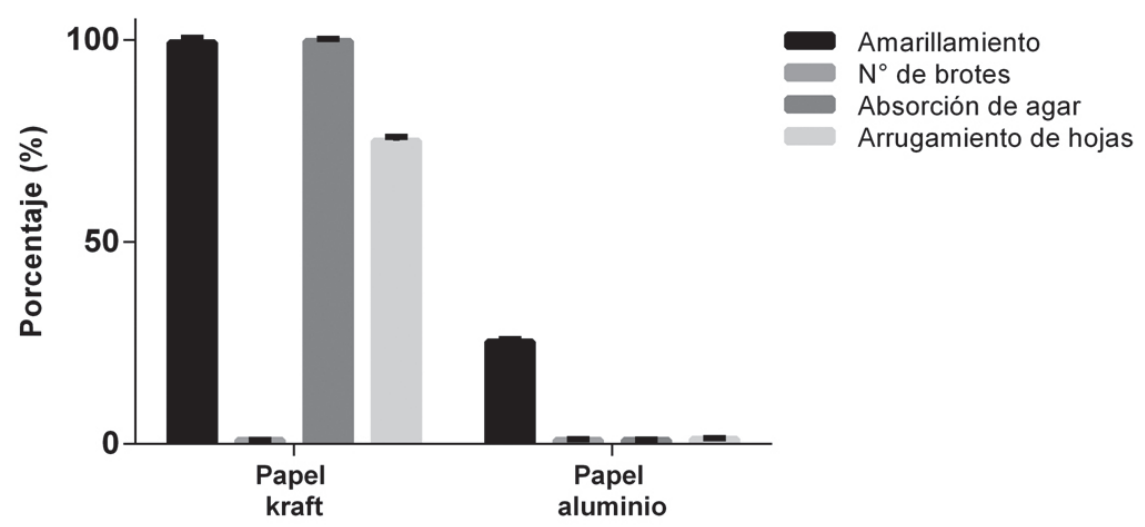

Figura 1. Efecto del tipo de cobertura en el desarrollo del cultivo in vitro de Colobanthus quitensis. Las columnas y barras representan la media \pm el error estándar (ES).

FiguRE 1. Effect of coverage type on the development of Colobanthus quitensis in vitro culture. Columns and bars represent mean \pm standard error (SE).

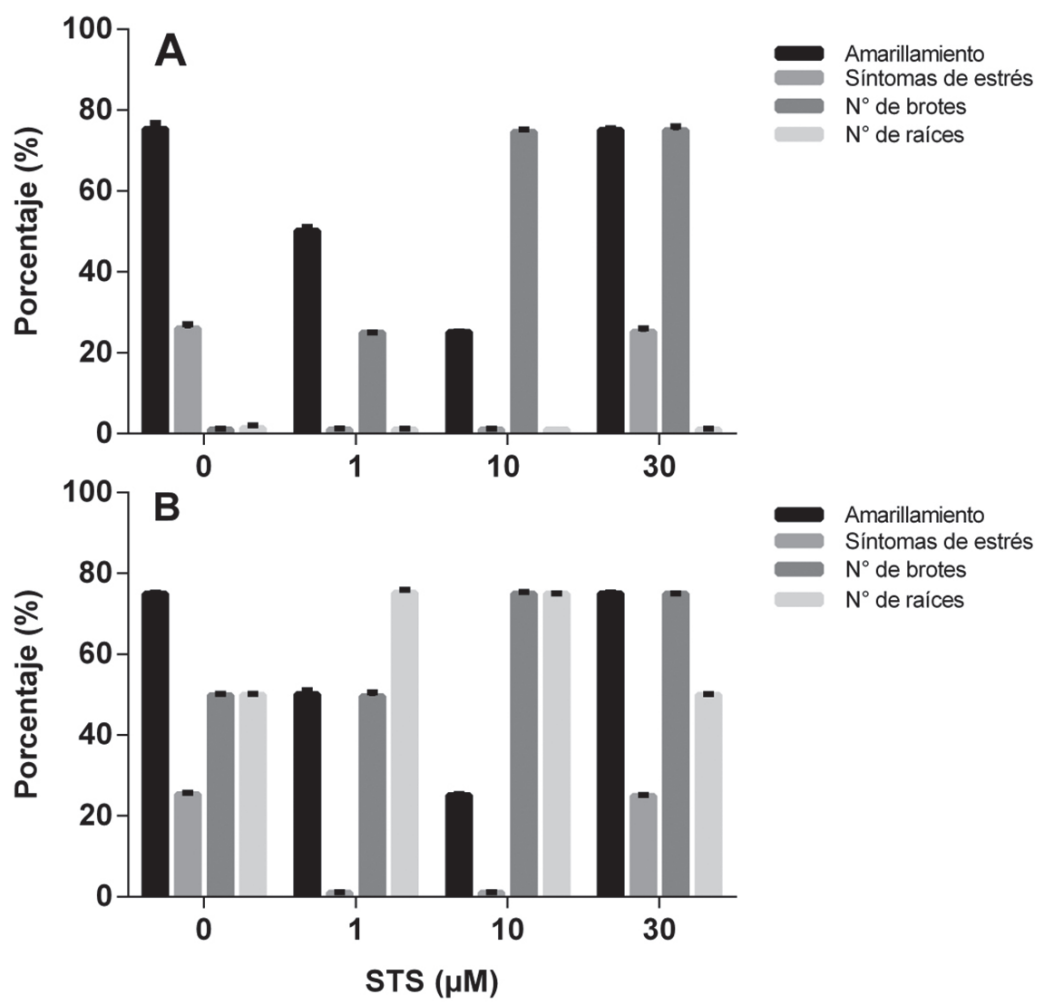

FIGURA 2. Efecto del tiosulfato de plata (STS) en la regeneración y la aparición de síntomas negativos (flores y muerte de brotes) durante el cultivo in vitro de Colobanthus quitensis, evaluado a los 14 días (A) y 28 días (B) de cultivo. Las columnas y barras representan la media \pm el error estándar (ES).

FIGURE 2. Effect of silver thiosulfate (STS) on regeneration and negative symptoms (flowers and shoots death) occurrence during the Colobanthus quitensis in vitro culture, evaluated at 14 days (A) and at 28 days (B) of cultivation. Columns and bars represent mean \pm standard error (SE). 
A los 14 días de introducido el cultivo en presencia de STS en el medio, se pudo observar que en todas las concentraciones usadas hubo un efecto positivo del inhibidor de etileno, con una disminución del amarillamiento (al 50 y $25 \%$ en 1 y $10 \mu \mathrm{M}$, respectivamente) y la no presencia de flores o muerte de las plántulas, considerados como síntomas de estrés (Fig. 2A). Se pudo apreciar un efecto estimulante del STS sobre la generación de nuevos brotes, observándose un incremento en todas las concentraciones estudiadas respecto del medio control (sin STS). La concentración mayor de STS $(30 \mu \mathrm{M})$, a pesar de presentar un elevado número de brotes, también mostró síntomas de amarillamiento y de estrés similares al control. Todos los parámetros evaluados se incrementaron, manteniendo la misma tendencia transcurridos 28 días del ensayo (Fig. 2B), donde además pudo ser evaluado el número de raíces, lográndose los mejores resultados en los medios con 1 y $10 \mu \mathrm{M}$ de STS (Fig. 2B). Al final del ensayo se corroboró que la concentración de $10 \mu \mathrm{M}$ de STS produjo los mejores efectos con menor amarillamiento $(50 \%$ menos que el medio control), sin síntomas de estrés y con el mayor número de brotes y raíces (Fig. 2B).

En la Fig. 3 podemos apreciar que durante los 42 días que se evaluó el efecto del frasco (magenta o de vidrio) sobre el cultivo, el frasco de vidrio (Fig. 3B) mostró los mejores resultados, donde ya a los 14 días se puede apreciar diferencias en cuanto a la aparición de síntomas de amarillamiento de las plántulas, con un $75 \%$ en los recipientes magenta (Fig. $3 \mathrm{~A}$ ) y un $25 \%$ en los frascos de vidrio (Fig. 3B). A los 28 días, a pesar de no observarse diferencias en la aparición de brotes entre ambos recipientes, sí es notoria la estimulación de raíces, con $25 \%$ de nuevas raíces en los frascos de vidrio. A los 42 días se duplica el amarillamiento en los explantes antiguos en los frascos de vidrio, pero hay un incremento en la aparición de nuevos brotes y raíces. Además, normalmente los subcultivos de estas plántulas y los explantes derivados (nuevos brotes $\mathrm{y} / \mathrm{o}$ pequeñas plántulas regeneradas) se realizan cada 5 semanas (35 días), por lo que se puede considerar que para esta especie es más factible el cultivo en frascos de vidrios de $100 \mathrm{ml}$.

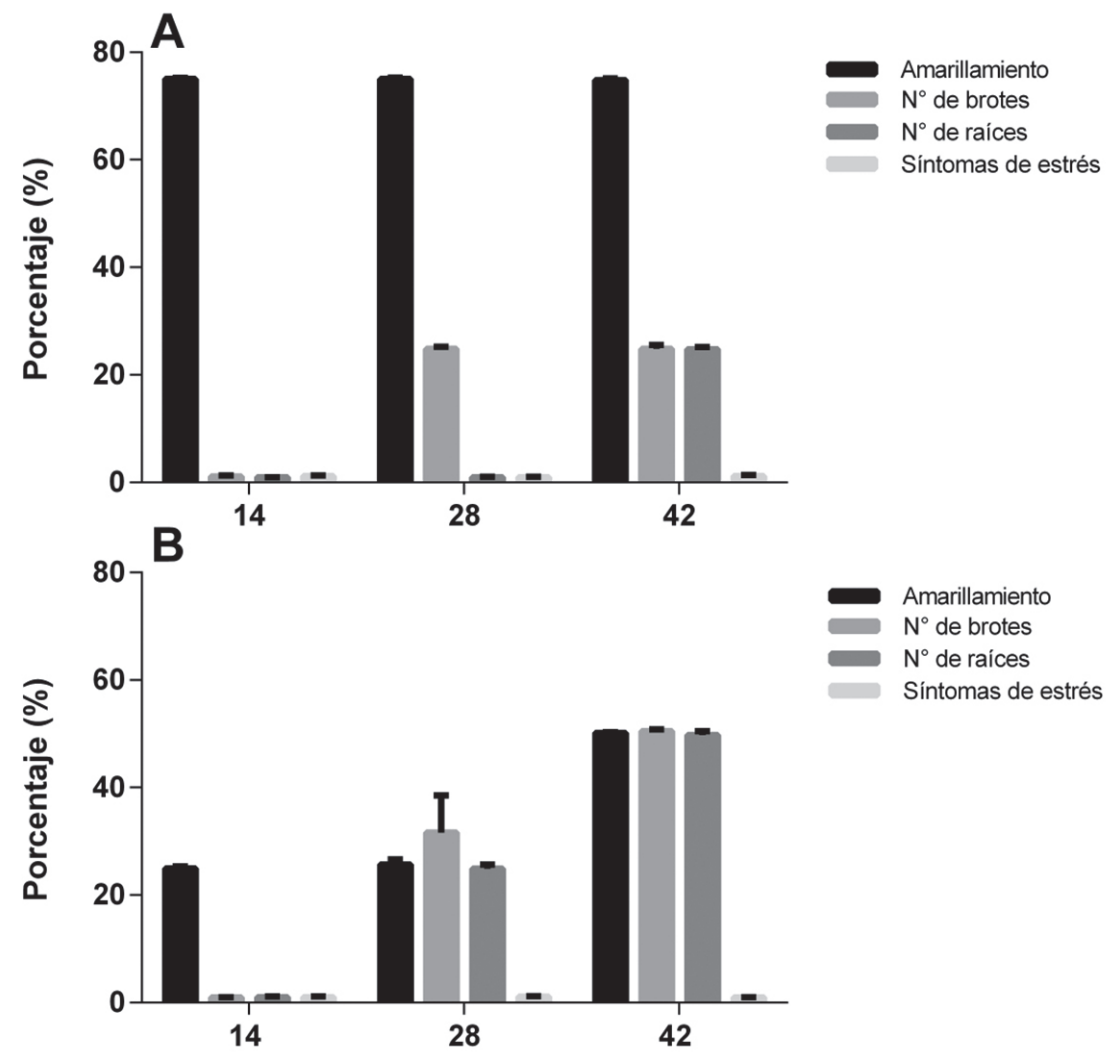

Figura 3. Efecto del tipo de recipiente en el desarrollo del cultivo in vitro de Colobanthus quitensis. A: Frasco Magenta, B: Frasco de vidrio. Las columnas y barras representan la media \pm el error estándar (ES).

Figure 3. Effect of vessel type on the development of Colobanthus quitensis in vitro culture. A: Magenta jar, B: Glass Jar. Columns and bars represent mean \pm standard error (SE). 
En la Fig. 4 se muestra que los rangos de intensidades menores $\left(28 \pm 0,5 \mu \mathrm{mol} \mathrm{m}{ }^{-2} \mathrm{~s}^{-1}\right.$ y $\left.45 \pm 2 \mu \mathrm{mol} \mathrm{m}^{-2} \mathrm{~s}^{-1}\right)$ no afectaron negativamente el desarrollo de los cultivos, con menores síntomas de estrés y amarillamiento de plántulas, además estas intensidades también mostraron mayor aparición de nuevos brotes y raíces. El rango de intensidad mayor $\left(72 \pm 2 \mu \mathrm{mol} \mathrm{m}^{-2} \mathrm{~s}^{-1}\right)$, si bien estimuló el desarrollo de brotes y raíces, también afectó negativamente el desarrollo de los cultivos con más amarillamiento y mayor aparición de los síntomas considerados de estrés, lo que ya se puede apreciar a los 7 días del cambio de los frascos a la zona que recibía esta intensidad lumínica (Fig. 4A).
En la Fig. 5 se muestra la respuesta de las plántulas a los diferentes medios evaluados, se puede comprobar que efectivamente el medio que contiene BAP $0,5 \mathrm{mg} \mathrm{L}^{-1}$ estimula el desarrollo de nuevos brotes y evita la aparición de otros síntomas de estrés, con 50\% menos de amarillamiento que los medios propuestos por Zúñiga et al. (2009) (Fig. $5 \mathrm{C})$. El medio con kinetina $2 \mathrm{mg} \mathrm{L}^{-1}$ estimula la generación de nuevos brotes, lo que se puede observar a los 28 días (Fig. 5A), en cambio ésta se mantiene estable en el tiempo a diferencia del medio con BAP que a los 42 días ya alcanza una inducción de nuevos brotes en un $75 \%$, con un notable $25 \%$ de inducción de sistema radicular (Fig. 5 C).

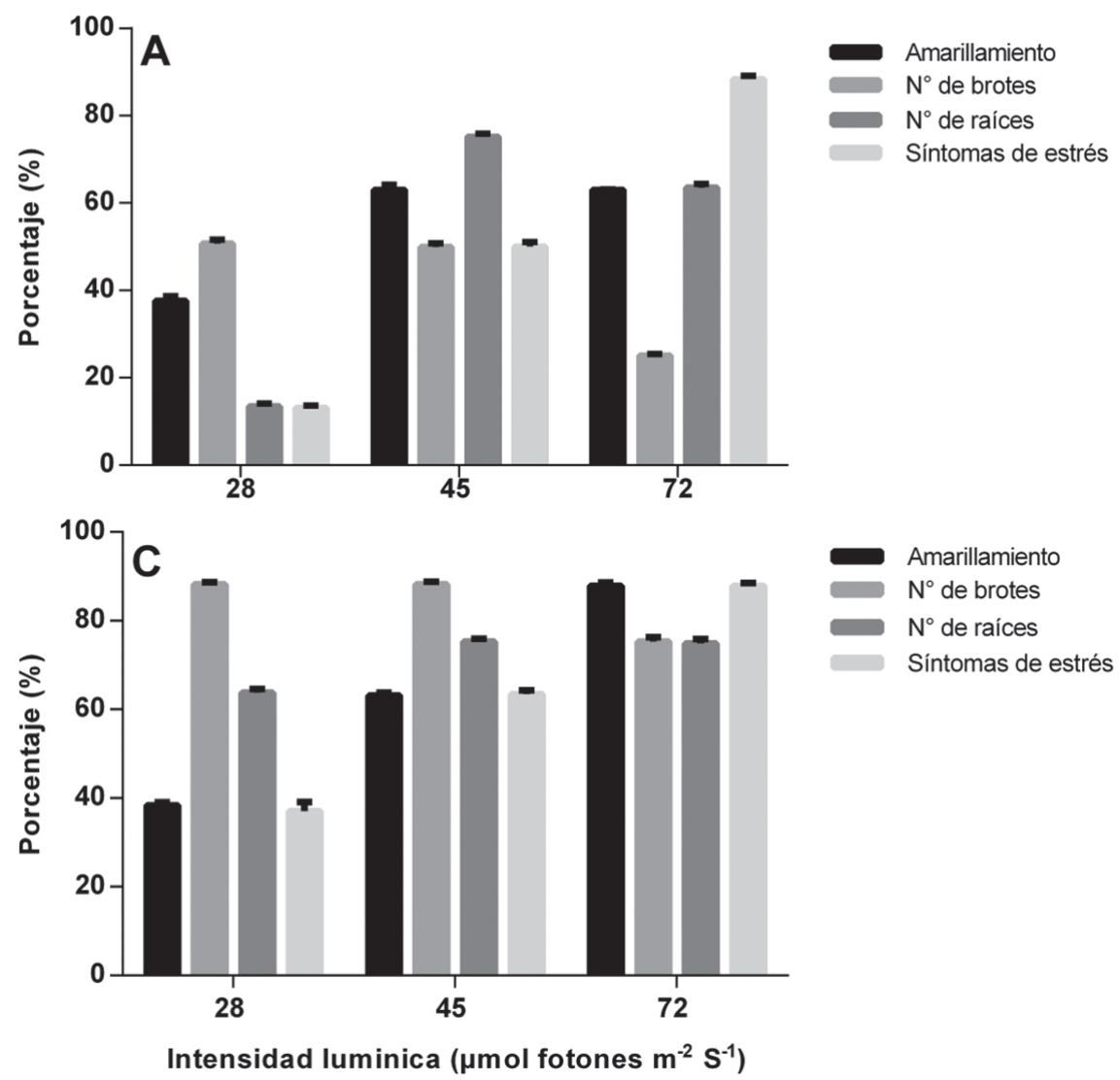

FiguRA 4: Incidencia de la intensidad lumínica en la regeneración y la aparición de síntomas negativos (flores y muerte de brotes) durante el cultivo in vitro de Colobanthus quitensis, a los 7 días (A) y 21 días (B). Las columnas y barras representan la media \pm el error estándar (ES).

FigURE 4: Incidence of light intensity on regeneration and negative symptoms (flowers and shoots death) occurrence during in vitro culture of Colobanthus quitensis, at 7 days (A) and 21 days (B). Columns and bars represent mean \pm standard error (SE). 

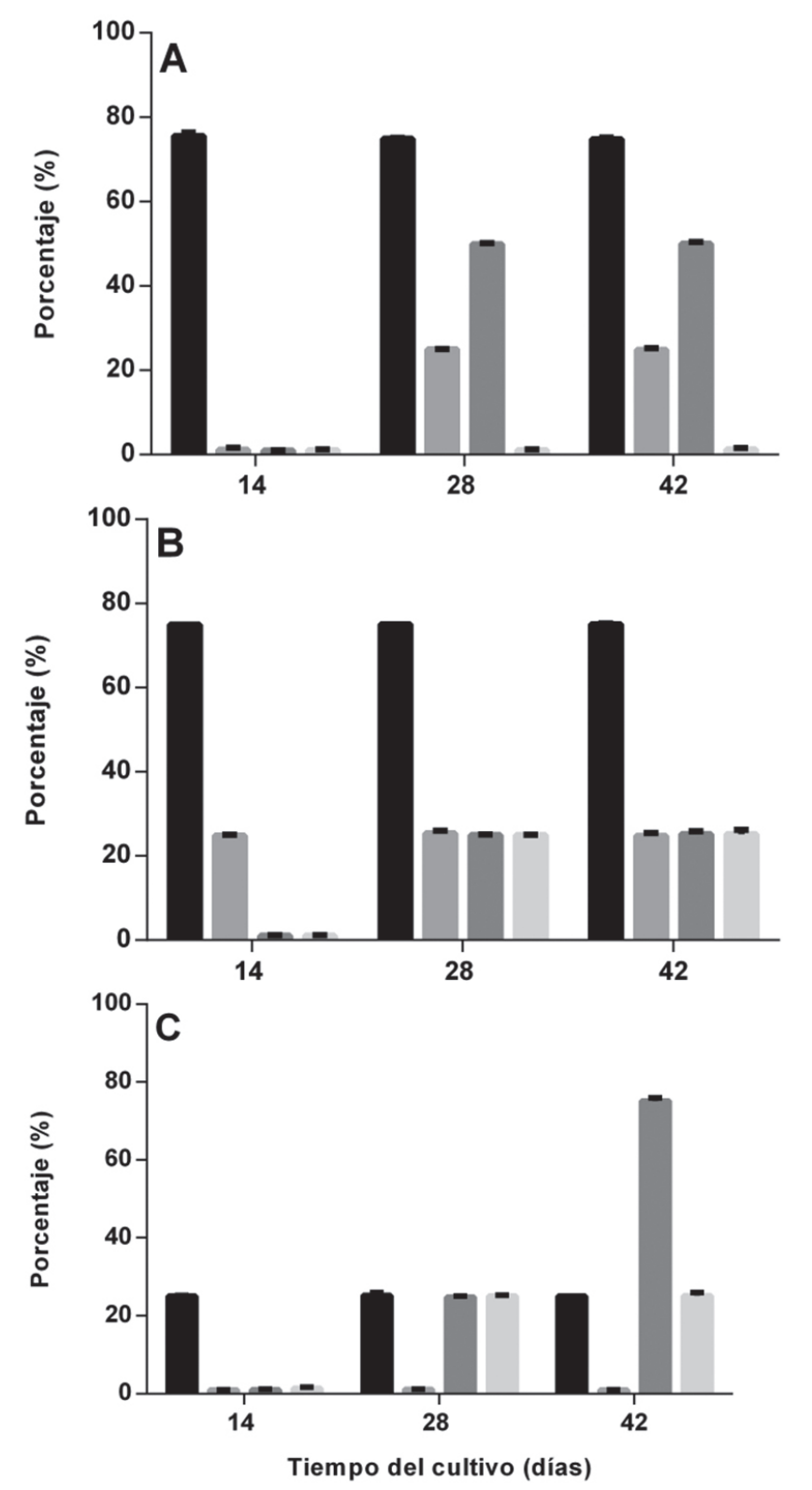

Amarillamiento

Síntomas de estrés

$\mathrm{N}^{\circ}$ de brotes

$\mathrm{N}^{\circ}$ de raíces

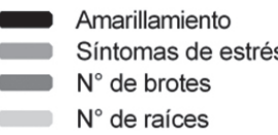

(

B: Kinetina 2 pH 5,6; C: BAP 0,5 pH 5,7. Ver más detalles en Tabla I. Las columnas y barras representan la media \pm el error estándar (ES).

FIGURE 5. Effect of culture medium (growth regulator and $\mathrm{pH}$ ) on Colobanthus quitensis in vitro culture. A: Kinetin 2 pH 4.5, B: Kinetin 2 pH 5.6, C: BAP 0.5 pH 5.7. See more details in Table I. Columns and bars represent mean \pm standard error (SE).

\section{DISCUSIÓN}

Para el desarrollo del cultivo in vitro es necesario garantizar tanto las condiciones físicas como químicas para la proliferación y buen desarrollo del cultivo. Dentro de los parámetros físicos destacan la luz, la temperatura y el recipiente donde el cultivo se desarrolla (Bhojwani \& Razdan 1996). En el mercado se dispone de una amplia variedad de recipientes para el desarrollo del cultivo de tejidos, desde frascos de vidrio hasta recipientes de diferentes tipos de plásticos; ejemplo: policarbonato, polipropileno y más recientemente poliestireno. Generalmente, los más usados son frascos de vidrio de diferentes volúmenes y frascos plásticos "Magenta TM", el uso de éstos incluye además los diferentes tipos de coberturas, que pueden incluir tapones de algodón no absorbentes, tapones de espuma de poliuretano, tapones de plástico, papel aluminio, tapas de acero inoxidable, y más recientemente varios tipos de tapas de plástico de polipropileno, PVC, formado por películas de polietileno, etc. (De Fossard 1976, Bhojwani \& Razdan 1996, Prakash 
et al. 2004). La selección del recipiente y la cobertura adecuada dependen de muchos factores, donde destacan los físicos y biológicos tales como: la entrada de la luz adecuada para el desarrollo del cultivo, el intercambio de gases y que impida la entrada de microorganismos potencialmente contaminantes; los factores químicos relacionados con la toxicidad que ciertos materiales pueden producir al cultivo, fundamentalmente con reiterados usos y esterilizaciones; y hasta los factores económicos relacionados con el alto costo de algunos de estos recipientes y sus coberturas (De Fossard 1976, Bhojwani \& Razdan 1996, Prakash et al. 2004). Los mejores resultados para la propagación de $C$. quitensis se obtuvieron al ocupar recipientes de vidrio (Fig. 3 B) y cobertura doble de papel aluminio comercial (Fig. 1), similares resultados obtuvieron McClelland \& Smith 1990, cuando compararon varios tipos de recipientes y sellados en el cultivo in vitro de varias especies.

En esta investigación se consideraron síntomas negativos al amarillamiento de plántulas, aparición de floración y muerte de plántulas, por constituir condiciones fisiológicas que disminuyen o evitan la proliferación de nuevos brotes y la mantención adecuada del estado fisiológico de los explantes (Tran Thanh Van 1981, Joyce et al. 2003). La producción de flores in vitro es indeseable además, porque en la mayoría de los casos, y también en C. quitensis, tanto éstas como las semillas que se producen, si es que llegan a formarse, suelen ser inviables. En esta investigación todos los síntomas negativos estudiados fueron disminuidos notablemente al aplicar una concentración de $10 \mu \mathrm{M}$ de STS al medio (Fig. 2). Esto evidencia que la incorporación del STS al medio de cultivo resulta efectivo en la disminución de síntomas de estrés probablemente causados por la acumulación de etileno en el frasco de cultivo. Por otro lado, la aplicación del STS estimuló la regeneración de brotes y raíces al compararse con el medio control. Uno de los factores físicos más importantes al interior del ambiente del cultivo in vitro es el etileno, una hormona vegetal gaseosa que juega un relevante papel fisiológico en el crecimiento y desarrollo de las plantas (Yang \& Hoffman 1984). En el cultivo in vitro, el etileno se produce durante la división celular y actúa como un inhibidor del crecimiento. Los iones de plata son un potente inhibidor de la acción fisiológica de esta hormona, se sabe que influyen en el potencial de regeneración en una variedad de plantas (Songstad et al. 1988, Chi et al. 1990). Mientras que el nitrato de plata $\left(\mathrm{AgNO}_{3}\right)$ es la fuente más utilizada de iones plata (Chi et al. 1990), el tiosulfato de plata (STS), también se ha utilizado para mejorar la regeneración de plantas (Hulme et al. 1992, Eapen \& George, 1997), la organogénesis foliar (Chae et al. 2012), el control de enraizamiento in vitro (Steinitz et al. 2010) y la embriogénisis somática en caña de azúcar (Nieves et al. 2007). Los estudios más recientes han mostrado que los iones de plata adicionados al medio de cultivo en forma de STS evitan que se forme el precipitado característico que se observa al adicionar $\mathrm{AgNO}_{3}$, lo que favorece la inducción de raíces adventicias y el crecimiento de nuevos brotes (Steinitz et al. 2010). Por otra parte, concentraciones de STS similares a las usadas en este trabajo produjeron un $40 \%$ más de brotes por explantes que el medio control (con BAP y ANA) en gloxinia (Sinningia speciosa (Lodd.) Hiern.) (Chae et al. 2012), lo que demuestra que la adición de STS en el medio de regeneración de C. quitensis, puede favorecer su regeneración y contrarrestar efectos negativos posiblemente causados por acumulación de etileno en el microambiente del recipiente de cultivo.

Se pudo observar que si bien las intensidades lumínicas promedio recibidas por las plantas, en las diferentes posiciones dentro del cuarto de cultivo, no afectan mayormente el desarrollo de nuevos brotes y raíces en $C$. quitensis, las intensidades más altas superiores a los 45 $\mu \mathrm{mol}$ de fotones $\mathrm{m}^{-2} \mathrm{~s}^{-1}$ favorecen la aparición de síntomas indeseados como amarillamiento y muerte de tejidos. Estos resultados coinciden con la literatura donde en estudios de propagación in vitro rutinariamente se emplean intensidades entre los 30-50 $\mu \mathrm{mol} \mathrm{m} \mathrm{m}^{-2} \mathrm{~s}^{-1}$, para obtener los mejores resultados. Las intensidades superiores pueden producir efectos perjudiciales como la inducción de oxidantes y hasta daño en el aparato fotosintético. Recientes estudios han mostrado alta frecuencia de regeneración de brotes adventicios en Aloe arborescens Mill. (Amoo et al. 2012) y en la conservación in vitro de Bacopa monnieri (L.) Wettst. (Sharma et al. 2012) usando intensidades lumínicas que fluctúan entre $30-40 \mu \mathrm{mol} \mathrm{m}^{-2} \mathrm{~s}^{-1}$.

En este estudio, el medio que contenía $0,5 \mathrm{mg} \mathrm{L}^{-1}$ de BAP pH 5,7 estimuló la regeneración de brotes y raíces en mayor porcentaje que el medio con $2 \mathrm{mg} \mathrm{L}^{-1}$ de KIN pH 4,5 informado anteriormente por Zúñiga et al. (2009), para esta misma especie. Además, produjo un menor porcentaje de efectos no deseados como amarillamiento y muerte de tejidos y aparición de floración anticipada, aspectos que no fueron considerados en la investigación de Zúñiga et al. (2009). La combinación y concentración de hormonas para la inducción de la regeneración de tejidos en el desarrollo del cultivo in vitro es un aspecto relevante, cuando se requiere optimizar un método de propagación para una especie determinada. Es ampliamente conocido que la respuesta fisiológica del explante, entre otros aspectos, depende de la especie, encontrándose en numerosos casos diferencias entre cultivares, subespecies y ecotipos. Zúñiga et al. (2009) usaron C. quitensis provenientes de una población antártica; en este trabajo se utilizaron explantes provenientes de una población patagónica de las cercanías de Punta Arenas. Observaciones realizadas en el laboratorio han permitido comprobar que no todas las poblaciones de C. quitensis responden igual a los medios empleados, con regeneraciones más tardías y aparición de efectos negativos a diferentes tiempos, efectos observados tanto in vitro como en condiciones de jardín común. Por otra parte se ha 
observado que, en esta especie, la germinación de semillas in vitro presenta porcentajes y tiempos de germinación diferenciales entre poblaciones. Aunque no evaluamos el efecto de las poblaciones, más estudios son requeridos para dilucidar a qué se puede deber esta respuesta diferencial, así como para definir el medio y condiciones de cultivo óptimo para la regeneración in vitro para cada población de $C$. quitensis. Varios estudios han mostrado adaptaciones morfofisiológicas y hasta diferenciación ecotípica en estudios con individuos de $C$. quitensis de diferentes procedencias (Gianoli et al. 2004, Bravo et al. 2007, Bascuñán et al. 2010, 2012, Cordero 2012), esto podría relacionarse con condicionamientos genéticos y fisiológicos de esta especie de acuerdo a su procedencia.

Los resultados obtenidos nos permiten concluir que es posible mejorar la eficiencia del cultivo in vitro para C. quitensis considerando aspectos físicos, químicos y biológicos que puedan adecuarse a las características genéticas y adaptaciones ecotípicas que esta especie puede presentar. Particularmente, los frascos de vidrio de tamaño pequeño (100 $\mathrm{ml}$ de capacidad), con una cobertura que posibilita el intercambio gaseoso, pero que a su vez permita el control de la entrada de agentes contaminantes, así como la adición al medio de un inhibidor de etileno como el STS, mejora la respuesta de $C$. quitensis al cultivo in vitro. Por otra parte, si bien las combinaciones hormonales estudiadas favorecen el desarrollo de brotes y raíces, más investigaciones son necesarias para establecer el medio óptimo para los individuos provenientes de poblaciones diferentes. La puesta a punto de esta metodología ofrece un sistema potencial para la propagación masiva de C. quitensis con implicaciones para la conservación de la colección de material de campo para la experimentación y su posterior investigación.

\section{AGRADECIMIENTOS}

Esta investigación fue financiada por los proyectos DIUC 208-112-044-1.0 e INACH T_03-09. Los autores quieren agradecer la colaboración técnica de I. Cid y C. Arcos. Y a los dos revisores anónimos por sus acertados comentarios y contribuciones.

\section{REFERENCIAS}

Alberdi, M., L.A. Bravo, A. Gutiérrez, M. Gidekel \& L.J Corcuera. 2002. Ecophysiology of Antarctic vascular plants. Physiologia Plantarum 115: 479-486.

Amoo, S.O., A.O. Aremu \& J. Van Staden. 2012. In vitro plant regeneration, secondary metabolite production and antioxidant activity of micropropagated Aloe arborescens Mill. Plant Cell, Tissue and Organ Culture 111: 345-358.

Bascuñán-Godoy, L., J. García-Plazaola, L.A. Bravo \& L.J.
CorCuERA. 2010. Leaf functional and micro-morphological photoprotective attributes in two ecotypes of Colobanthus quitensis from the Andes and Maritime Antarctic. Polar Biology 33:885-896.

Bascuñan-Godoy, L., C. Sanhueza, M. Cuba-Díaz, G.E. Zúñiga, L.A. Corcuera \& L.A. Bravo. 2012. Cold-acclimation limits low temperature induced photoinhibition by promoting a higher photochemical quantum yield and a more effective PSII restoration in darkness in the Antarctic rather than the Andean ecotype of Colobanthus quitensis Kunt Bartl (Cariophyllaceae). BMC Plant Biology 12: 114.

Bhojwani, S. \& M. Razdan. 1996. Plant Tissue Culture: Theory and Practice: Theory and Practice. Elsevier, $767 \mathrm{pp}$.

Bravo, L.A., F.A. Saavedra-Mella, F. Vera, A. Guerra, L.A. Cavieres, A.L. Ivanov, N.P.A. Huner \& L.J. Corcuera. 2007. Effect of cold acclimation on the photosynthetic performance of two ecotypes of Colobanthus quitensis (Kunth) Bartl. Journal of Experimental Botany 58(13): 3581-3590.

Chae, S.C., H.H. Kim, \& S.U. PArk. 2012. Ethylene inhibitors enhance shoot organogenesis of gloxinia (Sinningia speciosa). The Scientific World Journal Article ID 859381, 4 pp.

Chi, G.L., D.G. Barfield, G.E. Sim, \& E.C. Pua. 1990. Effect of silver nitrate and aminoethoxyvinylglycine on in vitro shoot and root organogenesis from seedling explants of recalcitrant Brassica genotypes. Plant Cell Reports 9: 195198.

Chwedorzewska, K.J. 2009. Terrestrial Antarctic ecosystems in the changing world: An overview. Polish Polar Research 30(3): 263-276.

Convey, P. 1996. The influence of environmental characteristics on the life history attributes of Antarctic terrestrial biota. Biological Reviews 71: 191-225.

Cordero, C. 2012. Caracterización y análisis de variabilidad morfológica y genética en poblaciones de Colobanthus quitensis (Kunth) Bartl. (Caryophyllaceae). Memoria para optar al título de Ingeniero en Biotecnología Vegetal. Universidad de Concepción, Los Ángeles, Chile 52 pp.

Cuba-Díaz, M. 2011. El clavelito antártico y los mecanismos que lo protegen del frío polar. Boletín Antártico Chileno 30(1, 2): 8-9.

De Fossard, R. 1976. Tissue culture for plant propagators. Department of Botany, University of New England. 409 pp.

Eapen, S. \& L. George. 1997. Plant regeneration form peduncle segments of oil seed Brassica species: Influence of silver nitrate and silver thiosulfate. Plant Cell, Tissue and Organ Culture 51: 229-232.

Gianoli, E., A. Zuñiga-Feest, M. Reyes-Dìaz, L.A. Bravo, \& L.J. CORCUERA. 2004. Ecotypic differentiation in morphology and cold resistance in populations of Colobanthus quitensis from the Andes of central Chile and the maritime Antarctic. Arctic, Antarctic and Alpine Research 36: 470475.

Hulme, J.S., E.S. Higgins, \& R. Shields. 1992. An efficient genotype independent method for regeneration of potato plants from leaf tissue. Plant Cell, Tissue and Organ Culture 31: 161-167.

Joyce, S.M., A.C. CASSELlS, \& S.M. JAIN. 2003. Stress and aberrant 
phenotypes in in vitro culture. Plant Cell, Tissue and Organ Culture 74: 103-121.

McClelland, M.T. \& M.A.L. Smith. 1990. Vessel type, closure, and explant orientation influence in vitro performance in five woody species. HortScience 25(7): 797-800.

McGray, J.B. \& T.A. Day. 1997. Size and characteristics of a natural seed bank in Antarctic. Arctic and Alpine Research 29(2): 213-216.

Moore, D.M. 1970. Antarctic terrestrial plants and their ecology. British Antarctic Survey Bulletin 23: 63-80.

Murashige, T. \& F. Skoog. 1962. A revised medium for rapid growth and bioassays with tobacco tissue cultures. Physiologia Plantarum 15: 473-497.

Nieves, N., M. Cid, D. Pina, Y. Lezcano \& J.M. Torne. 2007. Efecto del tiosulfato de plata sobre la embriogénesis somática y la semilla artificial de caña de azúcar. Agronomía Costarricense 31(2): 87-94.

PIERIK, R.L.M. 1987. In vitro culture of higher plants. Editorial Martinus Nijhoff Publishers. 348 pp.

Prakash, S., M.I. Hoque \& T. Brinks. 2004. Culture media and containers. In: Low cost options for tissue culture technology in developing countries, FAO/IAEA Division of Nuclear Techniques in Food and Agriculture, Vienna, pp: $29-40$.

Ruhland, C.T. \& T.A. Day. 2001. Size and longevity of seed banks in Antarctica and the influence of ultraviolet-B radiation on survivorship, growth and pigment concentrations of
Colobanthus quitensis seedlings. Environmental and Experimental Botany 45: 143-154.

Sharma, N., R. Satsang, R. Pandey, R. Singh, N. Kaushik, \& R.K. TYAGI. 2012. In vitro conservation of Bacopa monnieri (L.) using mineral oil. Plant Cell, Tissue and Organ Culture 111: 291-301.

Smith, R.I.L. 2003. The enigma of Colobanthus quitensis and Deschampsia antartica. In: A.H.L. Huiskes, W.W.C. Gieskes, J. Rozema, R.M.L. Schoro, S.M. van der Vies \& W.J. Wolff (eds.), Antarctic Biology in a Global Context. Leiden: Backhuys Publishers 2, pp. 34-239.

Songstad, D.D., D.R. Duncan \& J.M. Widholm. 1988. Effect of 1-amino cyclopropane-1-carboxylic acid, silver nitrate and norborndiene on plant regeneration from maize callus cultures. Plant Cell Rep. 7: 262-265.

Steinitz, B., N. Barr, Y. Tabib, Y. VaKnin \& N. Bernstein. 2010. Control of in vitro rooting and plant development in Corymbia maculate by silver nitrate. Plant Cell Report 29: 1315-1323.

Tran Thanh Van, K.M. 1981. Control of morphogenesis in in vitro culture. Annual Review of Plant Physiology 32: 291-311.

YANG, S.F. \& N.E. Hoffman. 1984. Ethylene biosynthesis and its regulation in higher plants. Annual Review of Plant Physiology 35(1): 155-189.

ZúNiga, G.E., P. Zamora, P. Ortega \& A. Obrecht. 2009. Micropropagation of Antarctic Colobanthus quitensis. Antarctic Science 21(2): 149-150.

Recibido: 22.03.13

Aceptado: 12.12.13 